\title{
Clinical Features of Acute Heart Failure During Sleep \\ - Prognostic Impact of a Prodrome in Patients With Severely Decompensated Acute Heart Failure Admitted at Midnight or Early Morning -
}

\author{
Masato Matsushita, MD, PhD; Akihiro Shirakabe, MD, PhD; Nobuaki Kobayashi, MD, PhD; \\ Hirotake Okazaki, MD, PhD; Yusaku Shibata, MD; Hiroki Goda, MD; \\ Saori Uchiyama, MD; Kenichi Tani, MD; Kazutaka Kiuchi, MD; \\ Noritake Hata, MD, PhD; Kuniya Asai, MD, PhD; Wataru Shimizu, MD, PhD
}

\begin{abstract}
Background: The features of sleep-associated acute heart failure (AHF) patients admitted at midnight or early morning (M/E) are unclear.

Methods and Results: Of 1,268 AHF patients screened, 932 were analyzed, and divided into 2 groups by admission time (M/E group, 23:00-06:59, $n=399$; daytime group, 07:00-22:59, $n=533$ ). Those in the M/E group were further divided by the presence of a prodrome: with ( $n=176$; prodrome group) or without $(n=223$; sudden onset group). The median time from symptom onset to hospitalization was significantly shorter in the M/E group (98 min; range, 65-170 min) than in the daytime group (123 min; range, 68-246 min). The 365-day HF event rate in the M/E group was significantly lower than that of the daytime group. On multivariate logistic regression modeling the M/E group was independently associated with a better outcome than the daytime group (OR, 0.673; $95 \% \mathrm{Cl}: 0.500-0.905)$. In the M/E group, the 365-day HF event rate was significantly lower in the prodrome group than in the sudden onset group. On multivariate logistic regression modeling, inclusion in the prodrome group was independently associated with a better outcome (OR, 0.544; 95\% Cl: 0.338-0.877).
\end{abstract}

Conclusions: AHF patients admitted during sleeping hours were not sicker than those admitted during the daytime. The absence of a prodrome, however, might be associated with future repeated HF events.

Key Words: Acute decompensated heart failure; Admission time; Night-time; Symptom; Vascular heart failure

A cute heart failure (AHF) occurs in various clinical settings. The Nohria-Stevenson classification and clinical scenario (CS) algorithm are widely recognized as pathophysiological classifications of AHF.1,2 The Nohria-Stevenson classification divides AHF into 4 subsets based on the presence of clinical symptoms of congestion and hypoperfusion. ${ }^{1}$ The CS categorizes AHF into 5 subsets based on systolic blood pressure (SBP) for the initial management of AHF in the emergency department. ${ }^{2} \mathrm{CS}-1$ is defined as high SBP. Most patients in this subset develop AHF abruptly and present with pulmonary edema rather than systemic volume overload. This type of heart failure $(\mathrm{HF})$ is regarded as "vascular" failure or "hypertensive" HF. CS-2 and CS-3 are characterized as normal or low blood pressure. Symptoms of the patients in these subsets develop gradually over days and include significant systemic congestion. This type of HF is regarded as "cardiac" failure or "normotensive-hypotensive" HF. These classifications are helpful for HF treatment and provide prognostic information.

Several studies have previously reported the association between the admission time and the clinical features of AHF. ${ }^{3-5}$ AHF hospitalization is more frequent at night than during the day, and AHF patients admitted at night are more likely to have high blood pressure and pulmonary edema. This means that night-time AHF can be characterized as vascular HF. In contrast, AHF patients hospitalized during the day are more likely to have normotensivehypotensive HF (cardiac failure).

An inverse relationship has been described between the blood pressure on admission and the prognosis of AHF.6,7 The difference in patient characteristics according to the admission time, including the long-term prognosis, in Asian populations, however, is still unclear. We therefore

Received November 20, 2018; revised manuscript received December 20, 2018; accepted December 21, 2018; J-STAGE Advance Publication released online January 31, 2019 Time for primary review: 1 day

Division of Intensive Care Unit, Nippon Medical School Chiba Hokusoh Hospital, Chiba (M.M., A.S., N.K., H.O., Y.S., H.G., S.U., K.T., K.K., N.H., K.A.); and Department of Cardiovascular Medicine, Nippon Medical School, Tokyo (W.S.), Japan

Mailing address: Akihiro Shirakabe, MD, PhD, ICU, Nippon Medical School Chiba Hokusoh Hospital, 1715 Kamagari, Inzai, Chiba 270-1694, Japan. E-mail: s6042@nms.ac.jp

ISSN-2434-0790 All rights are reserved to the Japanese Circulation Society. For permissions, please e-mail: cr@j-circ.or.jp 
1,268 patients who were admitted to the Intensive Care Unit

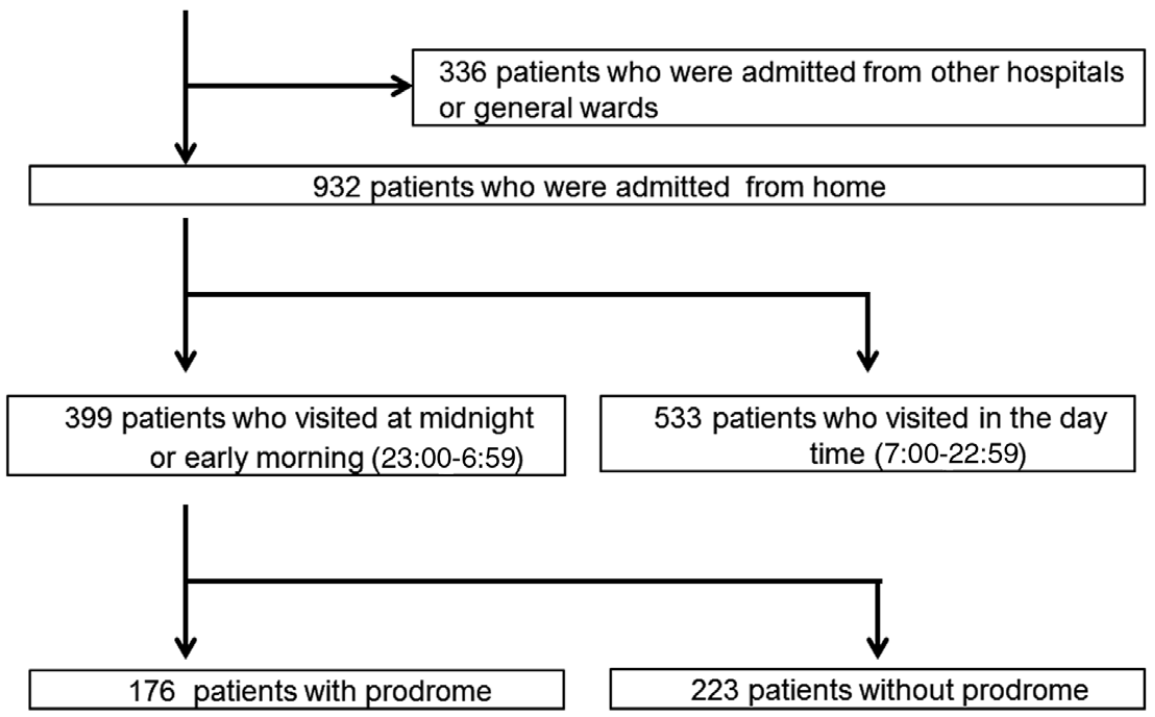

Figure 1. Subject selection at the Nippon Medical School Chiba Hokusoh Hospital intensive care unit between March 2001 and July 2017.

assessed the association between AHF during sleep and prognosis. Furthermore, although prehospital conditions including the time interval from symptom onset to hospitalization have been reported, ${ }^{\mathbf{8}}$ the presence of a prodrome has never been evaluated in AHF patients. We therefore focused on the presence of a prodrome because we hypothesized that patients with sudden onset would be easily decompensated by slight volume retention. This means that HF patients with sudden onset would have an insufficient cardiac reserve, which might result in future repeated HF events. Thus, the present study also assessed these prehospital conditions and the HF events of AHF patients admitted at midnight or in the early morning.

\section{Methods}

\section{Subjects}

A total of 1,268 patients with AHF admitted to the intensive care unit (ICU) of Nippon Medical School, Chiba Hokusoh Hospital, between March 2001 and July 2017 were enrolled in this study. Patients with HF caused by ST-T-elevated acute myocardial infarction were excluded from the study. In addition, 336 patients who were admitted from other hospitals or the general ward of the present hospital were excluded. Only AHF patients admitted from their homes were enrolled in the present study. A total of 932 AHF patients who were admitted from their homes to hospital were ultimately enrolled in this study (Figure 1).

AHF was defined as either new-onset HF or decompensation of chronic HF with symptoms sufficient to warrant hospitalization. Based on the 2016 ESC guidelines for the diagnosis of AHF, we diagnosed AHF on the measurement of plasma natriuretic peptide (i.e., B-type natriuretic peptide [BNP] $\geq 100 \mathrm{pg} / \mathrm{mL}$; class I, level A), 12-lead electrocardiogram (class I, level C), laboratory measurements (i.e., troponins, blood urea nitrogen [BUN], creatinine, sodium, potassium, glucose, liver function and complete blood count; class I, level C) and echocardiography (class I, level C). ${ }^{9}$ Furthermore, all of the included patients were given diuretics or vasodilators for the treatment of AHF. The treating physician in the emergency department diagnosed AHF based on these criteria $\leq 30$ min after admission and included the patient in the present study by filling out a form. All of the patients had a New York Heart Association (NYHA) functional class of either III or IV.

The patients who met any of the following criteria were admitted to the ICU: (1) requiring high-projectile oxygen inhalation (including mechanical support) to treat orthopnea; (2) requiring inotrope or mechanical support due to low blood pressure; and (3) requiring diuretics to improve general or lung edema. Patients with HF caused by acute coronary syndrome were excluded from the study. The treatment strategy was chosen by each physician.

\section{Procedure}

First, the patients were divided into 2 groups according to admission time. Patients who attended the hospital between 23:00 hours and 06:59 hours were assigned to the midnight/ early morning group (M/E group, $n=399)$, and those who attended between 07:00 hours and 22:59 hours were assigned to the daytime group (daytime group, $n=533$; Figures 1,2A). We evaluated the features of AHF associated with sleep in the present study. We defined M/E admissions based on the average bedtime of Japanese people $>50$ years of age (around 22:00-around 06:00 hours).

Second, the patients in the $\mathrm{M} / \mathrm{E}$ group were further divided into 2 groups according to the presence of a prodrome: with a prodrome $(n=176$; prodrome group) or without a prodrome $(n=223$; sudden onset group). Prodrome was defined as the presence of dyspnea on exertion or at rest and paroxysmal nocturnal dyspnea before the occurrence of presenting symptoms directly associated 

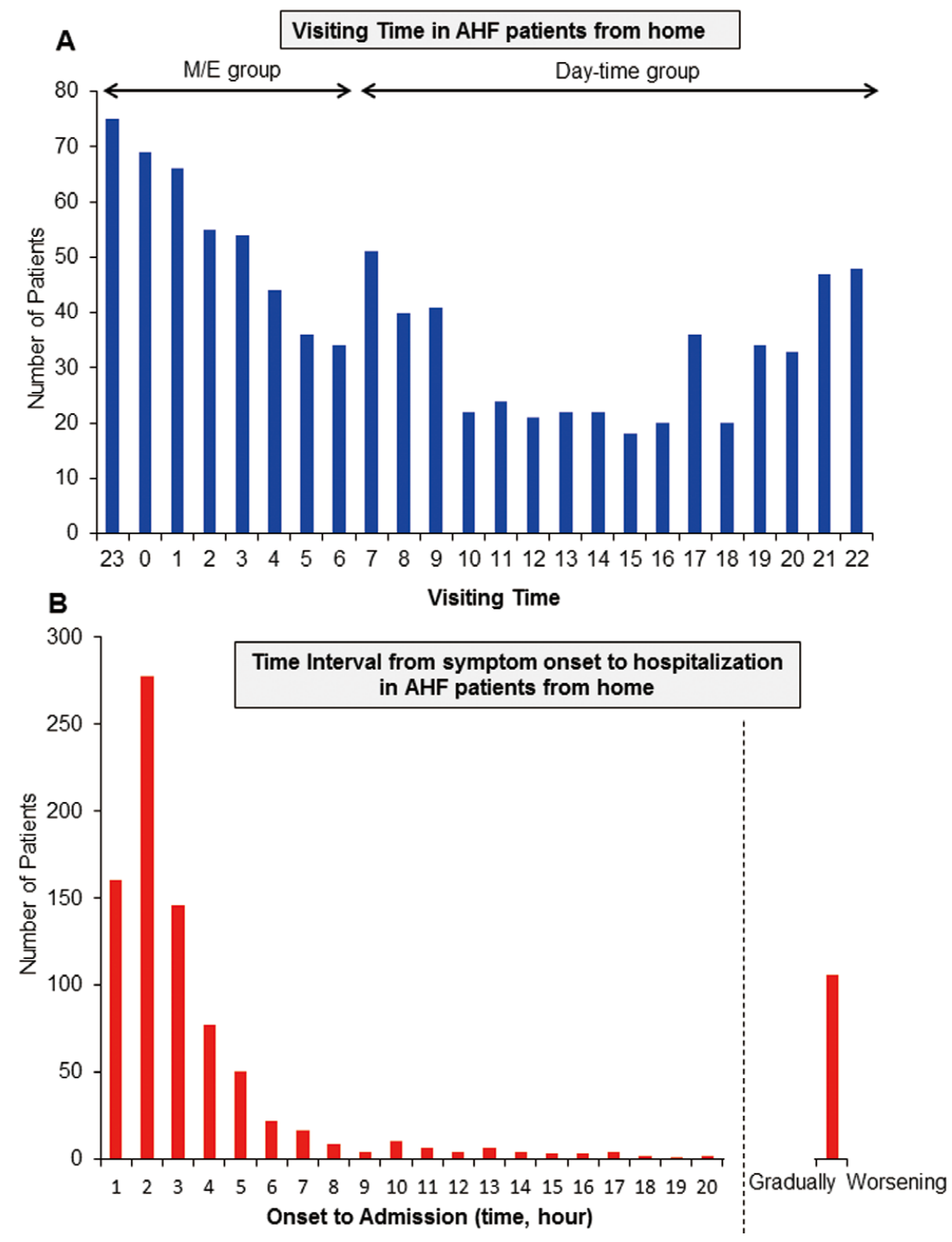

Figure 2. Distribution of acute heart failure (AHF) patients according to (A) time of admission and (B) onset-to-hospitalization time. M/E group, midnight/early morning group (patients who admitted between 23:00 and 06:59 hours); daytime group, patients who visited between 07:00 and 22:59 hours.

with visiting the emergency room. Sudden-onset AHF was categorized as AHF without prodrome.

We compared patient characteristics between the groups, including age, gender, presence of de novo or recurrent $\mathrm{HF}$, etiology of $\mathrm{HF}$, risk factors for atherosclerosis (diabetes mellitus, hypertension and dyslipidemia), vital signs on admission (SBP and heart rate), left ventricular ejection fraction (LVEF) on echocardiography on admission, presence of orthopnea, presence of chronic kidney disease (CKD), respiratory management (endotracheal intubation [ETI] and/or non-invasive positive pressure ventilation [NPPV]), arterial blood gas data on admission, laboratory data on admission (BUN, total bilirubin, hemoglobin,
BNP, C-reactive protein [CRP] and other variables) and medication during ICU admission. LVEF was calculated using the Teicholz method or Sympson's method on admission (Sonos 5500, Hewlett Packard, Palo Alto, CA, USA; or Vivid I, GE Yokogawa Medical, Tokyo, Japan).

The onset-to-hospitalization time was defined as the time interval from symptom onset to hospitalization. The distribution of onset-to-hospitalization care is shown in Figure 2B. The patients whose symptom onset time could not be determined due to gradual worsening were defined as "gradually worsening" in the present study. These findings were also compared between groups. 


\begin{tabular}{|c|c|c|c|c|}
\hline & $\begin{array}{c}\text { Total } \\
(n=932)\end{array}$ & $\begin{array}{l}\text { Day-time group } \\
\quad(n=533)\end{array}$ & $\begin{array}{l}\text { M/E group } \\
(n=399)\end{array}$ & P-value $^{\dagger}$ \\
\hline \multicolumn{5}{|l|}{ Characteristics } \\
\hline Age (years) & $75(66-81)$ & $75(66-82)$ & $74(66-80)$ & 0.145 \\
\hline Type (new onset) & $585(62.8)$ & 335 (62.9) & $250(62.7)$ & 1.000 \\
\hline Gender (male) & $618(66.3)$ & $348(65.3)$ & $270(67.7)$ & 0.484 \\
\hline Etiology (ischemia) & $394(42.3)$ & $213(40.0)$ & $181(45.4)$ & 0.108 \\
\hline \multicolumn{5}{|c|}{ Risk factors of atherosclerosis } \\
\hline Hypertension (yes) & $720(77.3)$ & $399(74.9)$ & $321(80.5)$ & 0.048 \\
\hline Diabetes mellitus (yes) & $422(45.3)$ & $238(42.8)$ & $194(48.6)$ & 0.084 \\
\hline Dyslipidemia (yes) & $466(50.0)$ & $262(49.2)$ & $204(51.1)$ & 0.596 \\
\hline \multicolumn{5}{|l|}{ Vital signs and status } \\
\hline $\mathrm{SBP}(\mathrm{mmHg})$ & $167(140-192)$ & $161(134-186)$ & $175(150-200)$ & $<0.001$ \\
\hline Heart rate (beats/min) & $114(96-132)$ & $111(92-130)$ & $120(100-134)$ & $<0.001$ \\
\hline LVEF (\%) & $36(26-49)$ & $36(26-49)$ & $36(25-48)$ & 0.934 \\
\hline Orthopnea (yes) & $805(86.4)$ & $441(82.7)$ & $364(91.2)$ & $<0.001$ \\
\hline CKD (yes) & $501(53.8)$ & $289(54.2)$ & $212(53.1)$ & 0.791 \\
\hline \multicolumn{5}{|l|}{ Respiratory management } \\
\hline ETI (yes) & $213(22.9)$ & $125(23.5)$ & $88(22.1)$ & 0.637 \\
\hline NPPV (yes) & $493(52.9)$ & $263(49.3)$ & $230(57.6)$ & 0.014 \\
\hline \multicolumn{5}{|l|}{ Arterial blood gas } \\
\hline $\mathrm{pH}$ & $7.29(7.17-7.39)$ & $7.31(7.19-7.40)$ & $7.27(7.15-7.35)$ & $<0.001$ \\
\hline $\mathrm{PCO}_{2}(\mathrm{mmHg})$ & $47(36-61)$ & $45(35-57)$ & $49(40-65)$ & $<0.001$ \\
\hline $\mathrm{PO}_{2}(\mathrm{mmHg})$ & $92(66-140)$ & $93(67-142)$ & $90(66-135)$ & 0.352 \\
\hline $\mathrm{HCO}_{3}-(\mathrm{mmol} / \mathrm{L})$ & $21.6(19.2-23.9)$ & $21.5(19.3-24.1)$ & $21.7(19.0-23.8)$ & 0.548 \\
\hline $\mathrm{SaO}_{2}(\%)$ & $95(89-98)$ & $96(91-98)$ & $95(88-98)$ & 0.010 \\
\hline Lactate (mmol/L) & $2.1(1.2-4.1)$ & $2.0(1.2-4.0)$ & $2.1(1.2-4.3)$ & 0.847 \\
\hline \multicolumn{5}{|l|}{ Laboratory data } \\
\hline Total bilirubin (mg/dL) & $0.5(0.4-0.8)$ & $0.6(0.4-0.8)$ & $0.5(0.4-0.7)$ & $<0.001$ \\
\hline BUN (mg/dL) & $23.9(18.0-35.2)$ & $25.3(18.3-36.3)$ & $22.3(17.7-32.5)$ & 0.064 \\
\hline Creatinine (mg/dL) & $1.18(0.90-1.80)$ & $1.21(0.93-1.81)$ & $1.15(0.85-1.77)$ & 0.236 \\
\hline Sodium (mmol/L) & $140(138-142)$ & $140(137-142)$ & $140(138-142)$ & 0.018 \\
\hline Potassium (mmol/L) & $4.3(3.9-4.7)$ & $4.4(4.0-4.8)$ & $4.1(3.8-4.6)$ & $<0.001$ \\
\hline Uric acid (mg/dL) & $6.7(5.4-8.0)$ & $6.8(5.5-7.9)$ & $6.7(5.3-8.0)$ & 0.429 \\
\hline Hemoglobin (g/dL) & $12.5(10.7-14.3)$ & $12.4(10.6-14.2)$ & $12.7(10.9-14.5)$ & 0.058 \\
\hline $\mathrm{CRP}(\mathrm{mg} / \mathrm{dL})$ & $0.47(0.16-1.47)$ & $0.53(0.19-1.74)$ & $0.38(0.13-1.08)$ & 0.001 \\
\hline \multicolumn{5}{|l|}{ Medication in ICU } \\
\hline Furosemide (yes) & $860(92.3)$ & $501(94.0)$ & $359(90.0)$ & 0.026 \\
\hline Nitroglycerin (yes) & $653(70.1)$ & $341(64.0)$ & $312(78.2)$ & $<0.001$ \\
\hline Nicorandil (yes) & $118(12.7)$ & $65(12.2)$ & $53(13.3)$ & 0.620 \\
\hline Carperitide (yes) & $462(49.6)$ & 279 (52.3) & $183(45.9)$ & 0.055 \\
\hline Dopamine (yes) & $173(18.6)$ & $99(18.6)$ & $74(18.5)$ & 1.000 \\
\hline Dobutamine (yes) & $165(17.7)$ & $107(20.1)$ & $58(14.5)$ & 0.030 \\
\hline ACEI/ARB (yes) & $381(40.9)$ & 204 (38.3) & $177(44.4)$ & 0.069 \\
\hline$\beta$-blocker (yes) & $250(26.8)$ & $146(27.4)$ & $104(26.1)$ & 0.709 \\
\hline Spironolactone (yes) & $349(37.5)$ & $193(36.2)$ & $156(39.1)$ & 0.375 \\
\hline
\end{tabular}

Data given as median (IQR) or $\mathrm{n}(\%)$. ${ }^{\dagger}$ Mann-Whitney U-test or $\chi^{2}$ test. ACEI, angiotensin-converting enzyme inhibitor; ARB, angiotensin II receptor blocker; BUN, blood urea nitrogen; CKD, chronic kidney disease; CRP, C-reactive protein; ETI, endotracheal intubation; ICU, intensive care unit; LVEF, left ventricular ejection fraction; M/E, midnight/ early morning; NPPV, non-invasive positive pressure ventilation; SBP, systolic blood pressure.

\section{Prognosis}

Short-term prognosis was evaluated as the duration of admission (duration of ICU stay and hospital stay) and in-hospital mortality, and long-term prognosis was evaluated as HF events, including all-cause death and readmission for $\mathrm{HF}$ in $\leq 365$ days. The patients were clinically followed up at a routine outpatient clinic. For the patients who were followed up at other institutes, prognosis was determined via telephone contact. The prognostic value in terms of the 365-day HF events was evaluated using a multivariate logistic regression model; and Kaplan-Meier curve analysis with significant differences calculated using the log-rank test was performed. 


\begin{tabular}{|c|c|c|c|c|}
\hline & $\begin{array}{c}\text { Total } \\
(n=932)\end{array}$ & $\begin{array}{l}\text { Day-time group } \\
\qquad(n=533)\end{array}$ & $\begin{array}{c}\text { M/E group } \\
(n=399)\end{array}$ & P-value ${ }^{\dagger}$ \\
\hline \multicolumn{5}{|l|}{ Type of onset } \\
\hline Gradual worsening (yes) & $106(11.4)$ & $90(16.9)$ & $16(4.0)$ & $<0.001$ \\
\hline Sudden onset (without prodrome) & $475(49.0)$ & $252(47.3)$ & $223(55.9)$ & 0.015 \\
\hline Onset to admission time (min) & $110(66-210)$ & $123(68-246)$ & $98(65-170)$ & 0.001 \\
\hline \multicolumn{5}{|l|}{ Short-term outcome } \\
\hline ICU hospitalization (days) & $4(3-6)$ & $4(3-6)$ & $4(3-6)$ & 0.001 \\
\hline Total hospitalization (days) & $26(16-42)$ & $27(17-42)$ & $24(16-41)$ & 0.261 \\
\hline In-hospital mortality (yes) & $64(6.9)$ & $44(8.3)$ & $20(5.0)$ & 0.066 \\
\hline
\end{tabular}

Data given as median (IQR) or $n(\%)$. ${ }^{\dagger}$ Kruskal-Wallis test or $x^{2}$ test. ICU, intensive care unit; M/E, midnight/early morning.

\section{Statistical Analysis}

All data were statistically analyzed using SPSS 22.0 (SPSS Japan Institute, Tokyo, Japan). All numerical data are expressed as median (range) or median (IQR), depending on normality. Normality was assessed using the ShapiroWilk W test. The Mann-Whitney U-test and Kruskal-Wallis test were used for comparisons between 2 or 3 groups. The chi-squared test was used to compare proportions. $\mathrm{P}<0.05$ was considered to indicate statistical significance.

A multivariate logistic regression analysis was performed to determine the odds ratio (OR) for the 365-day HF events with the daytime and sudden onset groups used for reference. All clinically relevant factors affecting the $\mathrm{HF}$ events, including SBP (per 10-mmHg increase), total bilirubin (per 1.0-mmol/L increase), sodium (per 1.0-mmol/L increase), CRP (per 1.0-mg/dL increase), hemoglobin (per $1.0-\mathrm{mg} / \mathrm{dL}$ increase) and LVEF (per 1\% increase), were selected for inclusion in the multivariate logistic regression hazard model associated with the 365-day HF events in each patient cohort. The multivariate logistic regression hazard model was developed by backward stepwise selection. The cumulative survival rates in each of the 2 groups were analyzed using Kaplan-Meier curves, and the log-rank test was used to calculate the statistical significance of the differences.

\section{Ethics Review Board}

The research ethics committee of Nippon Medical School, Chiba Hokusoh Hospital approved the study protocol. Regarding informed consent, we presented the content of the present study on a poster displayed at the institute as well as on the homepage, where it could be seen easily by everyone in accordance with the advice of the ethics committee.

\section{Results}

\section{Patient Characteristics}

The AHF patient cohort consisted of 618 male patients (66.3\%; median age, 75 years). A total of 585 patients (62.8\%) had new-onset HF, $394(42.3 \%)$ had ischemic heart disease, and $538(57.7 \%)$ had non-ischemic heart disease, including cardiomyopathy $(n=109)$, hypertensive heart disease $(n=168)$, valvular disease $(n=209)$ and others $(n=52)$. Most patients had orthopnea on admission (86.4\%). Median LVEF on admission was $36.0 \%$ (Table 1 ).

The majority of patients $(n=399,42.8 \%)$ visited the emergency room at midnight or in the early morning (between 23:00 and 06:59 hours [7h]), and the remaining patients $(n=533,57.2 \%)$ attended in the daytime (between 7:00 and 22:59 hours [17 h]; Figure 2A). The SBP and heart rate in the $\mathrm{M} / \mathrm{E}$ group were significantly higher than in the daytime group. In the $\mathrm{M} / \mathrm{E}$ group, orthopnea was more frequent, $\mathrm{pH}$ was significantly decreased, and $\mathrm{CO}_{2}$ was significantly increased compared with the daytime group. As a result, mechanical respiratory support, especially the use of NPPV, was needed significantly more often in the $\mathrm{M} / \mathrm{E}$ group than in the daytime group. Regarding laboratory findings, serum total bilirubin and CRP were significantly lower in the $\mathrm{M} / \mathrm{E}$ group than in the daytime group (Table 1). Furthermore, in the $\mathrm{M} / \mathrm{E}$ group, the use of nitroglycerin was significantly more frequent and that of dobutamine significantly less frequent than in the daytime group (Table 1).

\section{Onset Type and Prognosis}

The distribution of the time interval from symptom onset to hospitalization in the AHF patients admitted from home is described in Figure 2B. In all AHF patients, admission was achieved in $\leq 2 \mathrm{~h}$ after symptom onset in 437 patients $(47.9 \%)$ and $>2 \mathrm{~h}$ after symptom onset in 369 patients $(40.5 \%)$. There were 106 patients with unknown onset (i.e., gradually worsening patients; $11.6 \%$; Figure 2B). The median time interval from symptom onset to hospitalization was significantly shorter in the M/E group ( $98 \mathrm{~min}$; range, $65-170 \mathrm{~min}$ ) than in the daytime group (123 min; range, 68-246 min; $\mathrm{P}<0.001)$. Furthermore, gradually worsening patients were significantly less frequent in the $M / E$ group $(n=16,4.0 \%)$ than in the daytime group $(n=90$, $16.9 \% ; \mathrm{P}<0.001)$, and those without a prodrome were significantly more frequent in the $M / E$ group $(n=223$, $55.9 \%)$ than in the daytime group $(\mathrm{n}=252,47.3 \% ; \mathrm{P}=0.015$; Table 2).

Regarding the short-term prognosis, the length of ICU hospitalization was significantly shorter, and the rate of in-hospital mortality tended to be lower in the M/E group $(n=20,5.0 \%)$ than in the daytime group $(n=44,8.3 \%$; $\mathrm{P}=0.066$; Table 2). The Kaplan-Meier curves regarding the admission time are shown in Figure 3. The AHF patients who presented at midnight or in the early morning had significantly fewer HF events in 365 days than those who presented during the daytime (Figure 3A). On multivariate logistic regression modeling, midnight or early-morning AHF was independently associated with a better 365-day HF event rate (OR, 0.673; 95\% CI: 0.500-0.905; $\mathrm{P}=0.009$; Table 3). 


\section{HF events}
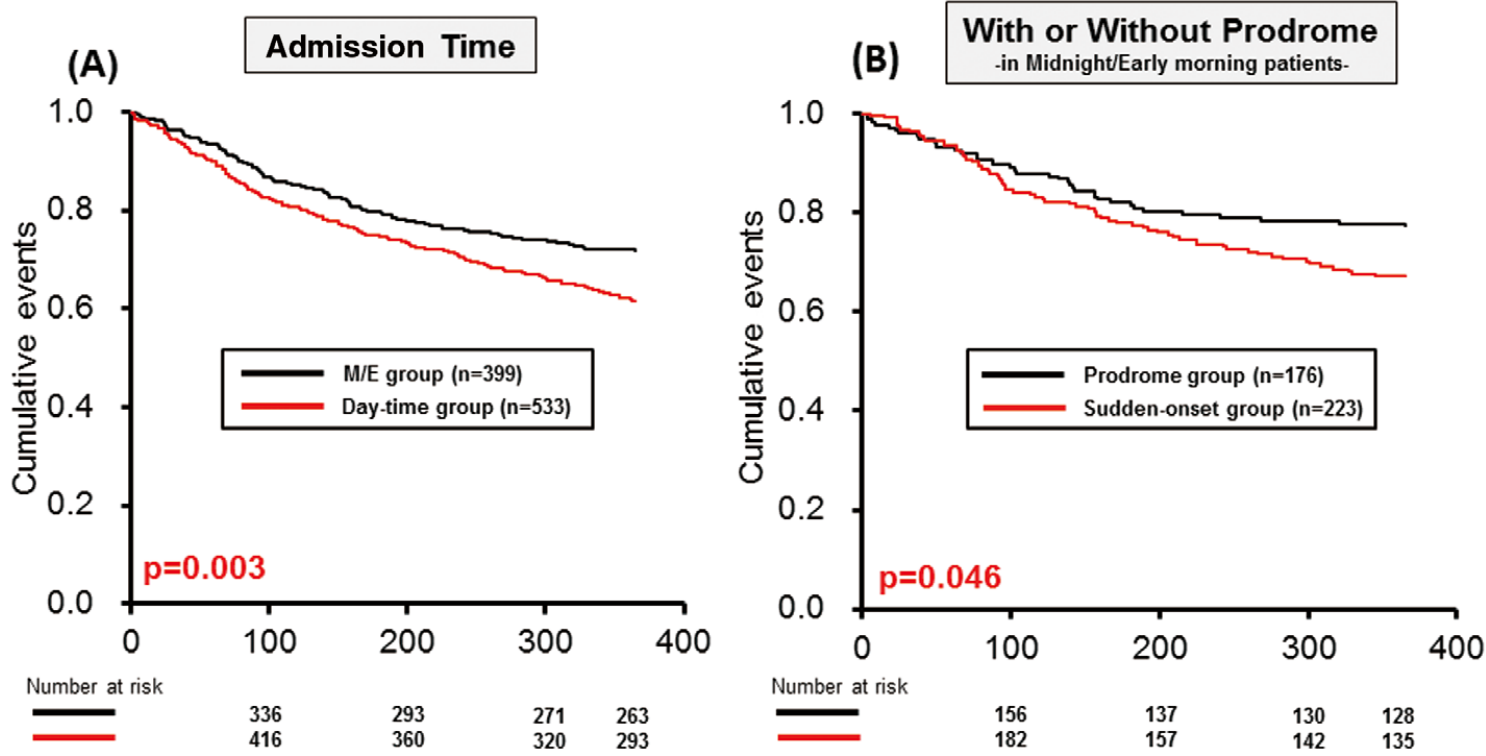

Figure 3. Kaplan-Meier cumulative heart failure (HF) event curves according to (A) admission time (daytime, 7:00-22:59 hours); M/E, midnight/early morning (23:00-6:59 hours), and (B) presence of prodrome in M/E acute HF patients.

\begin{tabular}{|c|c|c|c|c|c|c|}
\hline \multirow[b]{3}{*}{ All patients } & \multicolumn{3}{|c|}{ Univariate } & \multicolumn{3}{|c|}{ Multivariate } \\
\hline & OR & $95 \% \mathrm{Cl}$ & P-value & OR & $95 \% \mathrm{Cl}$ & P-value \\
\hline & & & & & & \\
\hline M/E AHF & 0.619 & $0.465-0.824$ & 0.001 & 0.673 & $0.500-0.905$ & 0.009 \\
\hline \multicolumn{7}{|l|}{ Laboratory data } \\
\hline SBP (per 10-mmHg increase) & 0.938 & $0.911-0.965$ & $<0.001$ & 0.959 & $0.925-0.995$ & 0.027 \\
\hline Creatinine (per 0.1-mg/dL increase) & 1.012 & $1.005-1.018$ & $<0.001$ & 1.011 & $1.003-1.019$ & 0.005 \\
\hline Total bilirubin (per 1-mg/dL increase) & 1.041 & $0.916-1.183$ & 0.537 & & & \\
\hline Sodium (per 1.0-mmol/L increase) & 0.954 & $0.931-0.979$ & $<0.001$ & 0.969 & $0.937-1.002$ & 0.062 \\
\hline CRP (per 1-mg/dL increase) & 1.010 & $0.992-1.029$ & 0.279 & 1.056 & $1.006-1.109$ & 0.028 \\
\hline Hemoglobin (per 1.0-mg/dL increase) & 0.998 & $0.985-1.012$ & 0.772 & & & \\
\hline LVEF (per $10 \%$ increase) & 0.931 & $0.866-1.000$ & 0.051 & & & \\
\hline \multicolumn{7}{|l|}{ M/E AHF patients } \\
\hline With a prodrome & 0.601 & $0.379-0.953$ & 0.030 & 0.544 & $0.338-0.877$ & 0.012 \\
\hline \multicolumn{7}{|l|}{ Laboratory data } \\
\hline SBP (per 10-mmHg increase) & 0.951 & $0.899-1.005$ & 0.076 & & & \\
\hline Creatinine (per 0.1-mg/dL increase) & 1.005 & $0.996-1.015$ & 0.278 & & & \\
\hline Total bilirubin (per 1-mg/dL increase) & 1.106 & $0.896-1.366$ & 0.349 & & & \\
\hline Sodium (per 1.0-mmol/L increase) & 0.919 & $0.864-0.976$ & 0.006 & 0.922 & $0.870-0.977$ & 0.006 \\
\hline CRP (per 1-mg/dL increase) & 1.080 & $0.987-1.181$ & 0.093 & 1.086 & $0.989-1.194$ & 0.085 \\
\hline Hemoglobin (per 1.0-mg/dL increase) & 1.006 & $0.993-1.020$ & 0.368 & & & \\
\hline LVEF (per $10 \%$ increase) & 0.900 & $0.786-1.031$ & 0.900 & 0.889 & $0.774-1.020$ & 0.094 \\
\hline
\end{tabular}

AHF, acute heart failure; HF, heart failure. Other abbreviations as in Table 1.

\section{Prodrome in AHF M/E Group Patients}

Most patient characteristics did not differ markedly between the prodrome group and the sudden onset group in the AHF M/E group patients. The major finding is that SBP was significantly higher and the use of nitroglycerin significantly more frequent in the sudden onset group than in the prodrome group (Table 4). In addition, the median time interval from symptom onset to hospitalization was significantly shorter in the sudden onset group $(88 \mathrm{~min}$; range, $59-169 \mathrm{~min})$ than in the prodrome group $(115 \mathrm{~min}$; 


\begin{tabular}{|c|c|c|c|}
\hline & $\begin{array}{l}\text { Prodrome group } \\
(n=176)\end{array}$ & $\begin{array}{l}\text { Sudden-onset group } \\
\qquad(\mathrm{n}=223)\end{array}$ & P-value \\
\hline \multicolumn{4}{|l|}{ Characteristics } \\
\hline Age (years) & $72(66-79)$ & $75(67-81)$ & 0.123 \\
\hline Type (new onset) & $116(65.9)$ & $134(60.1)$ & 0.252 \\
\hline Gender (male) & $120(68.2)$ & $150(67.3)$ & 0.914 \\
\hline Etiology (ischemia) & $80(45.5)$ & $101(45.3)$ & 1.000 \\
\hline \multicolumn{4}{|c|}{ Risk factors of atherosclerosis } \\
\hline Hypertension (yes) & $141(80.1)$ & $180(80.7)$ & 0.899 \\
\hline Diabetes mellitus (yes) & $83(47.2)$ & $111(49.8)$ & 0.615 \\
\hline Dyslipidemia (yes) & $86(48.9)$ & $118(52.9)$ & 0.480 \\
\hline \multicolumn{4}{|l|}{ Vital signs and status } \\
\hline $\mathrm{SBP}(\mathrm{mmHg})$ & $170(147-200)$ & $180(154-204)$ & 0.030 \\
\hline Heart rate (beats/min) & $120(100-132)$ & $119(102-136)$ & 0.443 \\
\hline LVEF (\%) & $36(25-48)$ & $37(26-50)$ & 0.240 \\
\hline Orthopnea (yes) & $158(89.8)$ & $206(92.4)$ & 0.378 \\
\hline CKD (yes) & $88(50.0)$ & $124(55.6)$ & 0.269 \\
\hline \multicolumn{4}{|l|}{ Respiratory management } \\
\hline ETI (yes) & $32(18.2)$ & $56(25.1)$ & 0.114 \\
\hline NPPV (yes) & $104(59.1)$ & $126(56.5)$ & 0.612 \\
\hline \multicolumn{4}{|l|}{ Arterial blood gas } \\
\hline $\mathrm{pH}$ & $7.29(7.17-7.36)$ & $7.26(7.13-7.35)$ & 0.299 \\
\hline $\mathrm{PCO}_{2}(\mathrm{mmHg})$ & $48(39-63)$ & $51(40-66)$ & 0.194 \\
\hline $\mathrm{PO}_{2}(\mathrm{mmHg})$ & $88(69-132)$ & $92(65-141)$ & 0.866 \\
\hline $\mathrm{HCO}_{3^{-}}(\mathrm{mmol} / \mathrm{L})$ & $21.7(18.8-23.7)$ & $21.7(19.2-23.9)$ & 0.584 \\
\hline $\mathrm{SaO}_{2}(\%)$ & $95(88-98)$ & $94(88-98)$ & 0.950 \\
\hline Lactate $(\mathrm{mmol} / \mathrm{L})$ & $1.8(1.1-3.7)$ & $2.5(1.3-4.8)$ & 0.119 \\
\hline \multicolumn{4}{|l|}{ Laboratory data } \\
\hline Total bilirubin (mg/dL) & $0.5(0.4-0.7)$ & $0.5(0.4-0.6)$ & 0.381 \\
\hline BUN (mg/dL) & $22.3(18.0-34.8)$ & $22.4(17.3-31.7)$ & 0.608 \\
\hline Creatinine (mg/dL) & $1.09(0.83-1.76)$ & $1.20(0.89-1.78)$ & 0.304 \\
\hline Sodium (mmol/L) & $140(138-142)$ & $140(138-142)$ & 0.387 \\
\hline Potassium (mmol/L) & $4.2(3.8-4.6)$ & $4.1(3.8-4.6)$ & 0.328 \\
\hline Uric acid $(\mathrm{mg} / \mathrm{dL})$ & $6.7(5.4-8.0)$ & $6.7(5.2-7.9)$ & 0.862 \\
\hline Hemoglobin (g/dL) & $12.9(11.6-14.5)$ & $12.4(10.6-14.5)$ & 0.245 \\
\hline CRP (mg/dL) & $0.48(0.13-1.11)$ & $0.33(0.12-1.04)$ & 0.336 \\
\hline \multicolumn{4}{|l|}{ Medication in ICU } \\
\hline Furosemide (yes) & $158(89.8)$ & $201(90.1)$ & 1.000 \\
\hline Nitroglycerin (yes) & $129(73.3)$ & $183(82.1)$ & 0.038 \\
\hline Nicorandil (yes) & $25(14.2)$ & $28(12.6)$ & 0.658 \\
\hline Carperitide (yes) & $84(47.7)$ & $99(44.4)$ & 0.544 \\
\hline Dopamine (yes) & $30(17.0)$ & $44(19.7)$ & 0.519 \\
\hline Dobutamine (yes) & $28(15.9)$ & $30(13.5)$ & 0.568 \\
\hline ACEI/ARB (yes) & $79(44.9)$ & $98(43.9)$ & 0.919 \\
\hline$\beta$-blocker (yes) & $38(21.6)$ & $66(29.6)$ & 0.085 \\
\hline Spironolactone (yes) & $81(46.0)$ & 75 (33.6) & 0.013 \\
\hline
\end{tabular}

Data given as median (IQR) or $\mathrm{n}(\%)$. ${ }^{+}$Mann-Whitney U-test or $x^{2}$ test. $\mathrm{SaO}_{2}$, arterial oxygen saturation. Other abbreviations as in Tables 1,3.

range, 71-175 min; $\mathrm{P}=0.019$; Table 5).

The short-term prognosis, including the ICU hospitalization, total hospitalization and in-hospital mortality, were not markedly different between the prodrome group and the sudden onset group, but the prognosis including the 365-day HF event rate was significantly poorer in the sudden onset group than in the prodrome group (Figure 3B). On multivariate logistic regression modeling, having a prodrome in the $\mathrm{M} / \mathrm{E}$ group was independently associated with a better 365-day $\mathrm{HF}$ event rate (OR, 0.544; 95\% CI: $0.338-0.877 ; \mathrm{P}=0.012$; Table 3).

\section{Discussion}

In the present study, the $\mathrm{M} / \mathrm{E}$ group $\mathrm{AHF}$ patients had better outcomes than the daytime group. The absence of a prodrome, however, was associated with a risk of future repeated $\mathrm{HF}$ events in the $\mathrm{M} / \mathrm{E}$ group. An association 


\begin{tabular}{|lccc|}
\hline \multicolumn{1}{|c|}{ Table 5. Type of Onset, Short-Term Outcome and Prodrome } & & \\
\hline & $\begin{array}{c}\text { Prodrome group } \\
(\mathbf{n = 1 7 9 )}\end{array}$ & $\begin{array}{c}\text { Sudden-Onset group } \\
(\mathbf{n = 2 2 5})\end{array}$ & P-value \\
Type of onset & $115(71-175)$ & $88(59-169)$ & 0.019 \\
$\quad$ Onset to admission time (min) & $4(3-6)$ & $4(3-5)$ & 0.171 \\
$\begin{array}{l}\text { Short-term outcome } \\
\text { ICU hospitalization (days) }\end{array}$ & $25(17-44)$ & $24(15-41)$ & 0.196 \\
Total hospitalization (days) & $9(5.1)$ & $11(4.9)$ & 1.000 \\
\hline In-hospital mortality (yes)
\end{tabular}

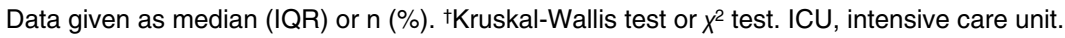

between the clinical characteristics and admission time in AHF has been demonstrated in several studies; ${ }^{3-5,10}$ the long-term prognosis of AHF according to admission time, however, has been described only in 1 previous study. ${ }^{5}$ Furthermore, there have been no reports on AHF patients admitted from midnight to early morning. In addition, this is the first study to suggest an association between admission time and the presence of a prodrome in AHF patients.

\section{Daytime and M/E Groups: Difference in Prognosis}

In the past decade, 2 primary phenotypes of AHF have been proposed. Acute decompensated cardiac failure was defined as the deterioration of cardiac performance over days to weeks leading to decompensation, while acute vascular failure was defined as acute hypertension and increased vascular stiffness. ${ }^{11}$ Cotter et al also reported that the concept of acute vascular failure is characterized by a transient volume shift from the peripheral veins to the pulmonary circulation with slight fluid accumulation. They described it as "fluid redistribution". The mechanisms underlying the fluid overload in some AHF patients might be related to redistribution rather than simple accumulation. In contrast, the pathophysiological basis of acute decompensated cardiac failure might be simple fluid retention (accumulation). ${ }^{12}$ In the concept of the CS algorithm, CS-1 is defined as high SBP, regarded as vascular failure or hypertensive HF, while CS-2 and CS-3 are characterized as the development of symptoms gradually over days, regarded as cardiac failure or normotensive-hypotensive HF. ${ }^{2}$

In the present study, the time interval from symptom onset to hospitalization was significantly shorter, and the patients with a prodrome were significantly less frequent in the $\mathrm{M} / \mathrm{E}$ group than in the daytime group. These clinical findings suggest that $\mathrm{M} / \mathrm{E} \mathrm{AHF}$ was more likely to be rapid onset than that noted during the day. Based on their examination of the Tokyo cardiac care unit network emergency medical service database, Shiraishi et al suggested that early-onset patients had a high SBP or pulmonary congestion, which was categorized as vascular failure. ${ }^{8}$ Patients with vascular failure cannot tolerate their abrupt symptoms for long and thus present to the emergency department immediately. $\mathrm{CO}_{2}$ retention and respiratory acidosis are caused by alveolar and pulmonary venous congestion. ${ }^{13,14}$ The pathophysiological feature of vascular failure is pulmonary edema, which occurs more often at night than during the day. ${ }^{15}$ The present findings also support the notion that urgent hospitalization with vascular failure (acute pulmonary edema) due to transient volume shift is more likely to occur at night than during the day.

Although the present results resemble those from previous studies, ${ }^{3,4}$ the time definition was different. In the present study, patients who visited the emergency department between 23:00 and 06:59 hours were assigned to the $\mathrm{M} / \mathrm{E}$ group, and those who visited between 07:00 and 22:59 hours were assigned to the daytime group. Previous reports have all used different definitions of daytime and night-time HF.,4 For example, Minami et al divided patients into 2 groups using 09:00 and 18:00 hours, ${ }^{4}$ and in our previous report, we divided patients into 2 groups using 08:00 and 20:00 hours. ${ }^{3}$ The present study defined night-time HF admission (M/E) as that occurring between 23:00 and 07:00 hours in order to focus on AHF occurring in association with sleep. Although the mechanisms underlying why most pulmonary edema cases occurred at night remain unclear, a study exploring the chronobiology of acute pulmonary edema suggested the potential impact of lying flat with a subsequent increased venous return as a potential precipitant in at-risk individuals. ${ }^{16}$ Sleep-associated AHF might be due more to a transient volume shift than fluid retention, and these patients can easily and rapidly recover with the use of NPPV, a vasodilator and a small amount of furosemide. Indeed, NPPV and vasodilators, including nitroglycerin, are used more frequently in cases of $M / E$ AHF for the treatment of vascular failure than in daytime AHF.

Some pathophysiological mechanisms regarding $\mathrm{HF}$ during sleep (i.e., sleep apnea, volume central shift, and abnormal circadian blood pressure rhythm) have been suggested. ${ }^{17,18}$ The pathophysiological mechanism of the onset of AHF during sleep, however, is unknown; furthermore, it is also difficult to identify the reason for the better outcome of the M/E AHF. The transient elevation of blood pressure caused by an abnormal circadian blood pressure rhythm might be an important mechanism underlying the onset of AHF during sleep. ${ }^{18}$ The sudden catecholamine surge induced by the symptom of dyspnea might be 1 reason for the elevation in blood pressure. Further studies will be required to clarify the mechanism underlying the onset of AHF during sleep.

In the clinical approach, the importance of the initial management before and/or after visiting the emergency department has been suggested,9,19,20 If the majority of sleep-associated AHF patients appear to have an acute onset, then the earlier initiation of therapy (i.e., NPPV and vasodilator) could be beneficial. These facts may explain the short-term admission to the ICU and the better prognosis of $\mathrm{M} / \mathrm{E} \mathrm{AHF}$ patients compared with daytime admissions.

\section{Importance of Prodrome in M/E Patients}

The relationship between the presence of a prodrome and 
the long-term prognosis in patients with AHF has never been reported. The present $\mathrm{M} / \mathrm{E}$ patients who lacked a prodrome (i.e., had sudden onset), however, had a worse long-term prognosis than those with a prodrome, but were more likely to have a short onset-to-hospitalization time and a short ICU stay.

Although we have no current standardized measurement scale for dyspnea, the pre-hospitalization symptom of dyspnea can be useful for detecting lung fluid accumulation before treatment. Therefore, the absence of dyspnea indicates only slight fluid accumulation. The main condition of the patients with sudden onset is transient volume shift from the peripheral veins to the pulmonary circulation, known as vascular AHF. Most M/E AHF patients present with vascular failure. Vascular AHF is easily and quickly treated by the early initiation of NPPV and/or vasodilator, which leads to a short ICU stay, as aforementioned. There are some differences, however, regarding the degree of fluid retention in vascular HF. The patients with no prodrome present with only slight fluid retention, which would, ultimately, be vascular failure. In contrast, the patients with prodrome present with some fluid accumulation, which may not be pure vascular failure and may involve some elements of cardiac failure. In general, vascular failure has a better prognosis than cardiac failure. ,7 $^{-7}$ Interestingly, however, in the present study AHF without prodrome (pure vascular failure) had a poorer outcome than AHF with prodrome (non-pure vascular failure). Although the associated mechanism has yet to be elucidated, the cardiac reserve may be involved. AHF patients with no prodrome may become easily decompensated because their cardiac reserve is not sufficient, which could lead to future HF events and thus a worse long-term prognosis. Even if patients in the $\mathrm{M} / \mathrm{E}$ group had a better long-term prognosis than those in the daytime group, we should still address their prodrome before treating these patients. The prodrome might be a sign that can help identify the actual phenotype of AHF.

\section{Study Limitations}

Several limitations associated with the present study warrant mention. First, because this was a single-center study, some patient-related biases might have been included. Second, the population was limited to only the patients admitted to the ICU, and AHF patients who were hospitalized in the general wards were excluded from the present study. Third, the decision to admit to the ICU was determined by each physician, which means the admission criteria to the ICU were unclear. Fourth, this was a retrospective study; therefore, some physicians might not have described the history of the present illness in detail. As a result, some data on prodromes might have been missed. Furthermore, given that we have no current standardized measurement scale of dyspnea, the criteria of dyspnea for each patient may have differed between physicians. Fifth, the present study did not clearly demonstrate the causal relationship between the admission time and AHF prognosis. Thus, other factors (i.e., SBP on admission) might directly affect the prognosis. Further studies to elucidate the relationship between admission time and AHF prognosis are required. Sixth, the exact onset time was not described in the past medical records of 20 patients, although they were not classified as having gradually worsening HF. These patients were excluded from the analysis of the duration from onset to admission. Finally, the prognostic value in terms of the 365-day HF events was evaluated using a multivariate logistic regression model. This model required complete follow-up for 365 days. In the present study, 77 patients $(8.3 \%)$ were not followed for a full 365 days. These patients were therefore excluded from the multivariate logistic model.

\section{Conclusions}

The AHF patients admitted during sleeping hours did not include sicker patients than those admitted during the daytime because they were mainly categorized as having vascular AHF caused by central volume shift. The absence of a prodrome, however, which can easily become decompensated with slight volume accumulation, might be associated with future repeated $\mathrm{HF}$ events, even in $\mathrm{M} / \mathrm{E} \mathrm{AHF}$ patients.

\section{Acknowledgments}

We are grateful to the staff of the ICU and the medical records office at Nippon Medical School, Chiba Hokusoh Hospital, for collecting the medical data.

\section{Funding Sources}

This research received no grants from any funding agency in the public, commercial or not-for-profit sectors.

\section{Disclosures}

The authors declare no conflicts of interest.

\section{References}

1. Nohria A, Tsang SW, Fang JC, Lewis EF, Jarcho JA, Mudge $\mathrm{GH}$, et al. Clinical assessment identifies hemodynamic profiles that predict outcomes in patients admitted with heart failure. $J$ Am Coll Cardiol 2003; 41: 1797-1804.

2. Mebazaa A, Gheorghiade M, Pina IL, Harjola VP, Hollenberg SM, Follath F, et al. Practical recommendations for prehospital and early in-hospital management of patients presenting with acute heart failure syndromes. Crit Care Med 2008; 36(1 Suppl): S129-S139.

3. Matsushita M, Shirakabe A, Hata N, Shinada T, Kobayashi N, Tomita K, et al. Association between the admission time and the clinical findings in patients with acute heart failure. J Cardiol 2013; 61: 210-215.

4. Minami Y, Kajimoto K, Sato N, Yumino D, Mizuno M, Aokage $\mathrm{T}$, et al. Admission time, variability in clinical characteristics, and in-hospital outcomes in acute heart failure syndromes: Findings from the ATTEND registry. Int J Cardiol 2011; 153: 102-105.

5. Pang PS, Teerlink JR, Boer-Martins L, Gimpelewicz C, Davison BA, Wang Y, et al. Day vs night: Does time of presentation matter in acute heart failure? A secondary analysis from the RELAX-AHF trial. Am Heart $J$ 2017; 187: 62-69.

6. Gheorghiade M, Abraham WT, Albert NM, Greenberg BH, O'Connor CM, She L, et al. Systolic blood pressure at admission, clinical characteristics, and outcomes in patients hospitalized with acute heart failure. JAMA 2006; 296: 2217-2226.

7. Ambrosy AP, Vaduganathan M, Mentz RJ, Greene SJ, Subacius $\mathrm{H}$, Konstam MA, et al. Clinical profile and prognostic value of low systolic blood pressure in patients hospitalized for heart failure with reduced ejection fraction: Insights from the Efficacy of Vasopressin Antagonism in Heart Failure: Outcome Study with Tolvaptan (EVEREST) trial. Am Heart J 2013; 165: $216-$ 225.

8. Shiraishi Y, Kohsaka S, Harada K, Sakai T, Takagi A, Miyamoto T, et al. Time interval from symptom onset to hospital care in patients with acute heart failure: A report from the Tokyo Cardiac Care Unit Network Emergency Medical Service Database. PLoS One 2015; 10: e0142017.

9. Ponikowski P, Voors AA, Anker SD, Bueno H, Cleland JG, Coats AJ, et al. 2016 ESC Guidelines for the diagnosis and treatment of acute and chronic heart failure: The Task Force for 
the diagnosis and treatment of acute and chronic heart failure of the European Society of Cardiology (ESC). Developed with the special contribution of the Heart Failure Association (HFA) of the ESC. Eur J Heart Fail 2016; 18: 891-975.

10. Kitzis I, Zeltser D, Kassirer M, Itzcowich I, Weissman Y, Laniado S, et al. Circadian rhythm of acute pulmonary edema. Am J Cardiol 1999; 83: 448-540, A9.

11. Cotter G, Felker GM, Adams KF, Milo-Cotter O, O'Connor $\mathrm{CM}$. The pathophysiology of acute heart failure: Is it all about fluid accumulation? Am Heart $J$ 2008; 155: 9-18.

12. Cotter G, Metra M, Milo-Cotter O, Dittrich HC, Gheorghiade M. Fluid overload in acute heart failure: Re-distribution and other mechanisms beyond fluid accumulation. Eur J Heart Fail 2008; 10: $165-169$.

13. Pappas L, Filippatos G. Pulmonary congestion in acute heart failure: From hemodynamics to lung injury and barrier dysfunction. Rev Esp Cardiol 2011; 64: 735-738 (in Spanish).

14. Shirakabe A, Hata N, Kobayashi N, Shinada T, Tomita K, Tsurumi M, et al. Clinical significance of acid-base balance in an emergency setting in patients with acute heart failure. $J$ Cardiol 2012; 60: 288-294.

15. Pasqualetti P, Casale R. Daily distribution of episodes of acute cardiogenic pulmonary edema. Cardiology 1997; 88: 509-512.
16. Manfredini R, Portaluppi F, Boari B, Salmi R, Fersini C, Gallerani M. Circadian variation in onset of acute cardiogenic pulmonary edema is independent of patients' features and underlying pathophysiological causes. Chronobiology Int 2000; 17: 705-715.

17. Yumino D, Redolfi S, Ruttanaumpawan P, Su MC, Smith S, Newton GE, et al. Nocturnal rostral fluid shift: A unifying concept for the pathogenesis of obstructive and central sleep apnea in men with heart failure. Circulation 2010; 121: 15981605.

18. Komori T, Eguchi K, Saito T, Hoshide S, Kario K. Riser pattern is a novel predictor of adverse events in heart failure patients with preserved ejection fraction. Circ J 2017; 81: 220-226.

19. Pang PS, Collins SP, Miro O, Bueno H, Diercks DB, Di Somma $\mathrm{S}$, et al. Editor's Choice: The role of the emergency department in the management of acute heart failure: An international perspective on education and research. Eur Heart J Acute Cardiovasc Care 2017; 6: 421-429.

20. Takahashi M, Kohsaka S, Miyata H, Yoshikawa T, Takagi A, Harada K, et al. Association between prehospital time interval and short-term outcome in acute heart failure patients. J Cardiac Fail 2011; 17: 742-747. 